\title{
A CLINICAL AND EPIDEMIOLOGICAL STUDY OF SUPERFICIAL FOLLICULITIS OF LEGS
}

\author{
R. Rama ${ }^{1}$, P. Guru Prasad ${ }^{2}$, P. Lakshmi3 3 , K. Anand Rao 4 , S. Amrutha Bindu ${ }^{5}$, Shaik Asha ${ }^{6}$ \\ ${ }^{1}$ Assistant Professor, Department of Dermatology, Andhra Medical College, Visakhapatnam. \\ ${ }^{2}$ Associate Professor, Department of Dermatology, Andhra Medical College, Visakhapatnam. \\ ${ }^{3}$ Retired Professor and HOD, Department of Dermatology, Andhra Medical College, Visakhapatnam. \\ ${ }^{4}$ Retired Associate Professor, Department of Dermatology, Andhra Medical College, Visakhapatnam. \\ ${ }^{5}$ Postgraduate, Department of Dermatology, Andhra Medical College, Visakhapatnam. \\ ${ }^{6}$ Postgraduate, Department of Dermatology, Andhra Medical College, Visakhapatnam.
}

\section{ABSTRACT}

Superficial folliculitis is the result of inflammation of the terminal part or ostium of the hair follicle due to infective or noninfective origin. It affects mainly young adult males in India. Clinically characterized by profuse eruption of superficial pustules, predominantly affects the lower legs without any systemic disturbances. It runs a chronic recurrent and relapsing course and usually resistant to treatment. The present work is undertaken to study the clinical and epidemiological pattern of the chronic superficial folliculitis of the legs.

\section{MATERIALS AND METHODS}

The study was carried out on patients attending the Outpatient Department of Dermatology, King George Hospital, affiliated to Andhra Medical College, Visakhapatnam, for a period of 1 year. It is a prospective study and a total of 100 cases were studied.

\section{RESULTS}

In this study, most common age group is in between 20-29 years. Males (95\%) outnumbered females (5\%) by the ratio of 19:1; $50 \%$ were casual workers, $95 \%$ presented with lesions with bilaterally symmetrical distribution affecting both the lower legs; $50 \%$ had mild pruritus, $67 \%$ showed exacerbations of recurrences during summer; $14 \%$ had history suggestive of atopy. In $85 \%$ gram stain, examination of the smear from the lesions showed Staphylococci. On culture, coagulase positive staphylococci were isolated from the lesions.

\section{CONCLUSION}

In the present study, superficial folliculitis of legs most commonly affects young adult males, classically involving the anterior aspect of lower legs. Most common causative organism is Staph aureus.

\section{KEYWORDS}

Superficial Folliculitis, Follicular Pustules.

HOW TO CITE THIS ARTICLE: Rama R, Prasad PG, Lakshmi P, et al. A clinical and epidemiological study of superficial folliculitis of legs. J. Evolution Med. Dent. Sci. 2016;5(65):4639-4641, DOI: 10.14260/jemds/2016/1057

\section{INTRODUCTION}

Superficial folliculitis is the result of inflammation of the terminal parts or ostium of the hair follicles. It may be of infective or non-infective origin.

Chronic superficial folliculitis of legs affects mainly young adult males in India. It is clinically characterized by profuse eruption of superficial and deep follicular pustules. It most commonly affects the lower legs followed by thighs. Individual lesion is dome shaped yellow pustules with central hair. Sometimes the lesions are surrounded by erythema; it persists for many years and is usually resistant to treatment. Recurrences are usually common during summer. There are no systemic disturbances. Sometimes hypergammaglobulinaemia may be present. It is usually asymptomatic, sometimes pruritus may be present. During acute attacks, pain may be present.

Financial or Other, Competing Interest: None.

Submission 27-06-2016, Peer Review 30-07-2016,

Acceptance 06-08-2016, Published 12-08-2016.

Corresponding Author:

Dr. P. Guru Prasad,

Department of Dermatology,

Venereology and Leprology,

Andhra Medical College,

Visakhapatnam,

Andhra Pradesh, India.

E-mail: gppatnala@yahoo.co.in

DOI: $10.14260 /$ jemds/2016/1057
The Pustular Dermatitis Atrophicans of the legs described in Lagos in West Africa, appears to be a similar condition. It occurs predominantly in males and affects symmetrically the anterior tibial surfaces of the legs, sometimes involving the thighs and forearms. Miliary pustules are followed by atrophic scars.

\section{MATERIALS AND METHODS}

The study was carried out on patients attending the Outpatient Department of Dermatology, King George Hospital, affiliated to Andhra Medical College, Visakhapatnam for a period of 1 year. It is a prospective study and a total of 100 cases were studied.

\section{Inclusion Criteria}

All cases of chronic folliculitis of legs with no treatment either topical or systemic for a minimum period of 3 months prior to the study and showing follicular papules, pustules with perilesional erythema or scaling on the legs with or without involvement of thighs, forearms and beard.

The study protocol included detailed history and clinical examination. More details were taken regarding occupation such as number of working hours, contact material if any, method of cleaning, whether co-workers affected or not Routine investigations including complete haemogram were done. Gram stain and culture of the material from the lesions 
were done and the strains were tested for the production of coagulase to know whether the strain isolated was pathogenic or non-pathogenic.

\section{RESULTS}

100 patients presenting with superficial folliculitis were included in the study and all parameters were evaluated. Most common age group affected is in between 20-29 years (41\%) and $30-39$ years (29\%); 95\% were males and male-tofemale ratio is $19: 1 ; 50 \%$ were casual workers followed by farmers; $67 \%$ have exacerbations during summer; $50 \%$ has pruritus and $30 \%$ had pain; $95 \%$ of cases showed bilaterally symmetrical distribution of lesions affecting both the lower legs. In all patients, involvement of lower legs is seen. In addition thighs were effected in $22 \%$, forearms in $12 \%$ of cases.

Direct microscopic examination of Gram stain showed Gram positive cocci in $80 \%$ of cases. In all cases, coagulase test was positive. Mannitol fermentation is positive in $82 \%$. Phenolphthalein test is positive in all cases. Salt agar test is positive in $80 \%$ cases. Majority of strains belong to phage group III and phage type $83 \mathrm{~A}$.

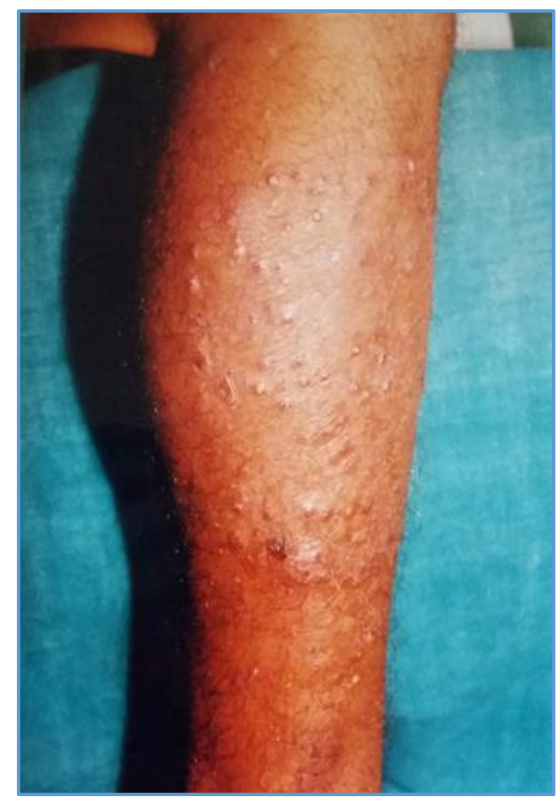

Fig.1: Chronic Folliculitis of Lower Leg

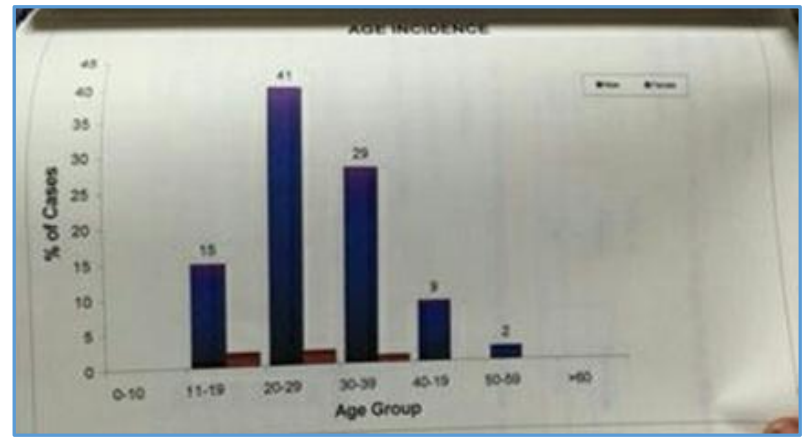

Image 1: Bar Diagram showing Age Distribution

\begin{tabular}{|l|c|c|}
\hline Sex & Number & Percentage \\
\hline 1. Females & 5 & $5 \%$ \\
\hline 2. Males & 95 & $95 \%$ \\
\hline \multicolumn{3}{|c|}{ Table 1: Showing Sex Distribution } \\
\hline
\end{tabular}

\begin{tabular}{|l|c|c|}
\hline \multicolumn{1}{|c|}{ Occupation } & Number & Percentage \\
\hline 1. Farmer & 16 & $16 \%$ \\
\hline 2. Fisherman & 6 & $6 \%$ \\
\hline 3. Mason & 8 & $8 \%$ \\
\hline 4. Carpenter & 4 & $4 \%$ \\
\hline 5. Casual worker & 50 & $50 \%$ \\
\hline 6. Students & 16 & $16 \%$ \\
\hline \multicolumn{2}{|c|}{ Table 2: Showing Occupation of Patients with Folliculitis } \\
\hline
\end{tabular}

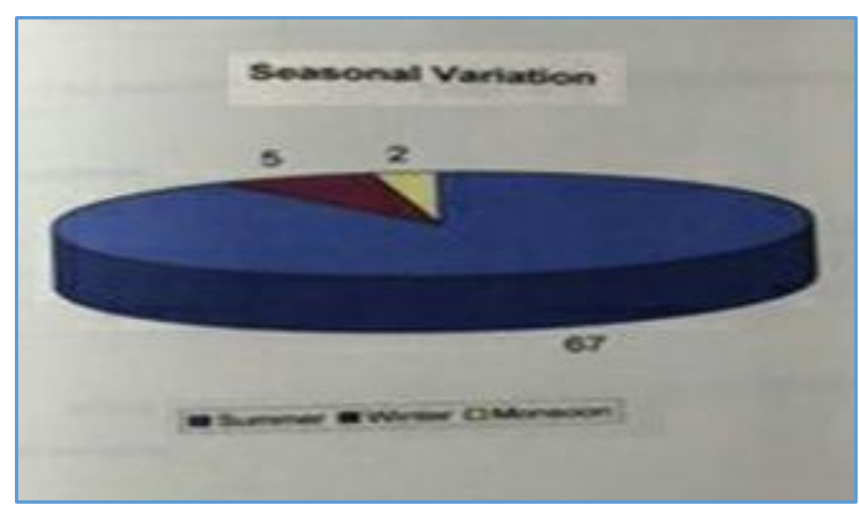

Image 2: Pie Chart showing Seasonal Variations

\begin{tabular}{|l|c|c|}
\hline $\begin{array}{c}\text { Distribution of } \\
\text { Lesions }\end{array}$ & Number & Percentage \\
\hline $\begin{array}{l}\text { 1. Bilaterally } \\
\text { symmetrical }\end{array}$ & 95 & $95 \%$ \\
\hline 2. Asymmetrical & 5 & $5 \%$ \\
\hline \multicolumn{2}{|c|}{ Table 3: Showing Distribution of Lesions } \\
\hline
\end{tabular}

\begin{tabular}{|c|c|c|}
\hline Sites Affected & Number & Percentage \\
\hline $\begin{array}{l}\text { Lower Legs } \\
\text { a) Both } \\
\text { b) One }\end{array}$ & $\begin{array}{c}95 \\
5\end{array}$ & $\begin{array}{c}95 \% \\
5 \%\end{array}$ \\
\hline $\begin{array}{c}\text { In Addition to } \\
\text { Lower Legs the } \\
\text { following Sites } \\
\text { were Affected }\end{array}$ & & \\
\hline Thighs & 22 & $22 \%$ \\
\hline Forearms & 12 & $12 \%$ \\
\hline Beard area & 7 & $7 \%$ \\
\hline Anterior chest & 2 & $2 \%$ \\
\hline
\end{tabular}

\section{DISCUSSION}

The present study deals with the clinical and epidemiological study of 100 cases of chronic folliculitis of legs attending the Outpatient Department of KGH, Visakhapatnam.

\section{Age}

In the present study, the commonest age group affected was 20-29 years (43\%) followed by $30-39$ years (30\%). This is in agreement with the previous studies conducted by Wright RC in 1992[1] and Desai SC et al in 1964[2] who also reported that chronic folliculitis of legs mainly affects young adults. Dr. PVS Prasad in 1997 reported $48 \%$ of patients in the age group 16-

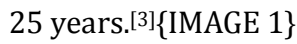

Males outnumbered the females in the present study by ratio of 19:1. Similar higher incidence among males was observed by Desai et al in 1964[2] and Wright RC in 1992[1] and Sugathan $P$ et al in 1973. ${ }^{[4]}$ \{TABLE 1\} 
The high incidence among males may be due to the fact that males are more involved in manual labour and exposed to factors which may predispose to chronic folliculitis.

\section{OCCUPATION}

Majority of patients in the present study were casual workers; $50 \%$ in various occupations like stone cutting units, cycle shops, garages followed by farmers $(16 \%)$.

Exposure to various material like stone dust, machine oil may account for the high incidence of chronic folliculitis in casual workers. Dr. PVS Prasad in 1997 reported 44\% patients were agricultural labourers. ${ }^{[3]}$

Higher incidence in farmers may be due to contact with mud and pesticides causing disruption of barrier function resulting in infection. \{TABLE 2$\}$

\section{Seasonal Variation}

Majority of cases (67\%) showed exacerbations of recurrences during summer. Similar seasonal aggravation reported by Sugathan $\mathrm{P}$ et al[4] in 1973 . They reported aggravations in summer in $50.6 \%$ of cases. Aggravation was also reported due to factors like contact with mud, oil, stone dust. Similar aggravation factors were also reported by S Jacob Zacariah et al in their study in 1973. \{IMAGE 2\}

History suggestive of atopy reported in $14 \%$ of cases. Predisposition to staphylococcal infections in atopic individuals may be the reason for the high incidence of atopy reported in the present study. Leydon JJ, Marples RR, Klingmann AM in 1974 reported high number of S. aureus in atopic eczema.

Mild pruritus reported in 50\% and pain during acute attacks in 30\%. Dr. PVS Prasad in 1997 reported pruritus as the predominant symptom in $86 \%$ patients.[3]

In $95 \%$ of cases, the lesions showed bilaterally symmetrical distribution affecting both the lower legs. Similar distribution also reported by Sugathan $\mathrm{P}$ et al[4] in 1973, Tiwari VP et al in 1987, Wright RC[1] in 1992. \{TABLE 3)

Lower legs affected in all 100 cases. In 28\%, lesions are confined to the lower legs; $22 \%$ had lesions on front of the thighs in addition to legs and in $12 \%$ forearm also involved in addition to legs and thighs. \{TABLE 4$\}$

On culture, coagulase positive staphylococci alone were isolated from the lesions. Sugathan P et al,[4] Tiwari VP et al,
Parik DA et al, CR Srinivas, Desai SC et al,[2] Kandhani et al and Dr. PVS Prasad in 1997[3] also reported coagulase positive staphylococci as the commonest organism.

On direct smear examination after gram stain, clusters of staphylococci were seen along with plenty of pus cells in $80 \%$ of cases. Only pus cells seen in $20 \%$ may be due to technical error.

\section{Biochemical Tests}

All strains isolated from lesions were shown to be coagulase positive, mannitol fermentation was reported to be positive in $82 \%$ of cases.

\section{Phage Typing}

Majority of the strains were not typable with the set of phages employed. Of the typable strains, majority belonged to phage group III (B). Most prevalent phage type was group III (A). Similar observation reported by Pasricha et al.[5]

\section{CONCLUSION}

Chronic folliculitis of leg runs in chronic recurrent and relapsing course. Most commonly affecting the young adult males. Classical sites are lower legs followed by thighs usually show exacerbation of lesions in summer. Predominant symptom is pruritus. Commonest organism is phage group IIIA coagulase positive staphylococcus.

\section{REFERENCES}

1. Wright RC. Traumatic folliculitis of the leg: a persistent case associated with use of a home epilating device. J Am Acad Dermatol 1992;27(5 pt 1):771-2.

2. Desai SC, Shah BH, Modi PJ, et al. Therapy of resistant pyogenic folliculitis on legs in adult males with hypergammaglobulinaemia. Indian J Dermatol Venereol Leprol 1964;30(2):89-97.

3. Prasad P, Anandhi V, Jaya M. Chronic folliculitis-a clinicoepidemiological study. Indian J Dermatol Venereol Leprol 1997;63(5):304-6.

4. Sugathan P, Zacariah J, Joy M. Folliculitis cruris pustulosa et atrophicans. Indian J Dermatol Venerol Leprol 1973;39:35-40.

5. Parischa A, Bhujwala RA, Shriniwas. Bacteriological study of pyoderma. Indian Journal of Pathology \& Bacteriology 1972;15(4):131-8. 